ARTICLE

\title{
Single-use plastic packaging in the Canadian food industry: consumer behavior and perceptions
}

Tony R. Walker (1D ${ }^{1 凶}$, Eamonn McGuinty $\mathbb{B}^{1}$, Sylvain Charlebois (D) $^{2}$ \& Janet Music (D ${ }^{2}$

Single-use plastic food packaging is a major contributor to the global solid waste problem. Although the food industry is developing strategies to reduce single-use plastic packaging, it needs to better understand consumer awareness and attitudes about the issue. As consumer awareness about single-use plastic waste outpaces private sector practices, this study considered personal motivation factors, government policies, and innovative solutions related to single-use plastic food packaging. This Canada-wide study surveyed 1014 consumers and their willingness to pay premiums for sustainable food packaging alternatives and motivations to reduce single-use plastic waste. Overwhelmingly, most (93.7\%) respondents were personally motivated to reduce consumption of single-use plastic food packaging. Canadians were highly motivated to reduce single-use plastic food packaging, but less willing to pay for sustainable alternatives. While environmental concerns were more critical than food safety, Canadians acknowledged that sustainable packaging alternatives were more desirable than outright plastic bag bans, despite not willing to pay for them. Using approaches that consider multiple driving factors on consumer behavior and opinions towards use of single-use plastic food packaging, limitations, recommendations and future research are proposed.

\footnotetext{
${ }^{1}$ School for Resource and Environmental Studies, Dalhousie University, Halifax, NS, Canada. ${ }^{2}$ Faculty of Management, Dalhousie University, Halifax, NS, Canada. ${ }^{凶}$ email: trwalker@dal.ca
} 


\section{Introduction}

onsumption of single-use plastics has been identified as a global environmental pollution crisis (UNEP, 2018). Plastics have become entrenched in day-to-day lives in everything humans do. Because of its utility, the global plastics production volume has doubled every decade (Geyer et al., 2017). The amount of plastic produced globally since 1950 is estimated at 9.2 billion metric tons (MT) and upwards of 6.9 billion MT of plastic has ended up in landfills or worse, "leaking" into the environment (Brooks et al., 2018). Since creation of plastic polymers in the 1950s, single-use plastic production, use and mismanagement has resulted in devastating impacts on marine, terrestrial and aquatic ecosystems (UNEP, 2014, 2018). From bags to food containers, plastics are omnipresent in society and many experts are concerned about the impact of plastic on ecosystem and human health (Worm et al., 2017; Karbalaei et al., 2018). Addressing global environmental threats of single-use plastics requires government regulation, business innovation, and individual behavior change for cleaner production and potential environmental and economic benefits.

Consumer plastics are designed to be durable and strong, which benefit society through longevity and safety but causes issues with disposal and recycling (Plastics Europe, 2017). Plastics consumed for single-use is the largest market globally, where growth has been accelerated by a shift from reusable to single-use containers. Plastic waste generation has increased from $1 \%$ in 1960 to $>10 \%$ by 2005 in high-income developed countries (Jambeck et al., 2015). Over half of the world's mismanaged plastic waste is generated by just five countries: China, Indonesia, the Philippines, Vietnam, and Sri Lanka (Brooks et al., 2018). These five countries have been overwhelmed by plastic waste exports from developed countries that have exacerbated the single-use plastic problem (Liu et al., 2018). Since the 1950s, roughly $40 \%$ of the 448 million MT (2015) of plastic produced every year is designed for single use, much of it for packaging intended to be discarded within minutes after purchase (Geyer et al., 2017). Assessing global plastic packaging flows comprehensively found that most plastic packaging is used only once and $95 \%$ of the value of the material, worth USD $\$ 80-120$ billion annually, is lost to the economy (World Economic Forum, 2016).

Plastic waste awareness, especially from single-use plastic packaging, is linked to recent increases in public attention (Schnurr et al., 2018). None of the commonly used plastics in society are fully biodegradable and as a result have accumulated (rather than decomposing) in natural environments and landfills (Walker and Xanthos, 2018; Karbalaei et al., 2019). Furthermore, public understanding of the correlation between fossil fuel extraction and use of petroleum for plastic production has gained increased attention in recent years (Avery-Gomm et al., 2019). In a recent global study, an estimated $9 \%$ of plastic waste has ever been recycled, $12 \%$ incinerated, and the remaining $79 \%$ has accumulated in landfills or leaked into the environment, as of 2015 (Geyer et al., 2017). Thus, impacts on natural environments from plastic waste accumulation has become an increasing concern for consumers (Avery-Gomm et al., 2019; Walker and McKay, 2021).

While Canada's recycling figures are comparable to global averages, Canada claims to be moving toward a circular economy for plastics by pursuing zero-plastic waste and improving beyond the $89 \%$ of total plastics destined for landfills, incineration or leakage into the environment (Walker and Xanthos, 2018). By virtue of reactive measures by governments, corporations, nongovernment organizations and individuals, we are now seeing emerging trends of plastic bag bans, fines, taxes, and industry phase-outs of certain single-use plastics (Xanthos and Walker, 2017; Schnurr et al., 2018; Adam et al., 2020; Clayton et al., 2020;
Bezerra et al., 2021). The range of measures are considered to be tiered by performance-based approaches, market instruments, and voluntary initiatives (CCME, 2018). Additionally, the rise of consumer changes is placing significant pressures on industry and governments to take action, including promotion of the circular economy (Ellen MacArthur Foundation, 2018). The circular economy thinking is widely used within countries for closed-loop waste recycling and Canada has been a major exporter of recyclable materials (Liu et al., 2018). Although consumers are aware of environmental problems caused by food packaging, they are unaware of sustainable packaging solutions (e.g., circular economy or alternatives) (Scott and Vigar-Ellis, 2014; Ketelsen et al., 2020). Consumers play an important role in market adoption of alternatives because they are decision-makers when purchasing plastic packaging products (Fernqvist et al., 2015).

In Canada, single-use plastic pollution has been recognized as an environmental problem (Walker and Xanthos, 2018). There is a growing trend in consumer demand for more corporate responsibility and in response corporations are seeking strategies to reduce their single-use plastic packaging. While maintaining the focus on Canada, global best practices and barriers including the integration of circular economy approaches, extended producer responsibility (EPR) and reverse logistics processes was reviewed to help determine a path forward for emerging trends associated with negative externalities of single-use plastics. Applying circular economy principles to global plastic packaging could transform the plastics economy and reduce negative externalities (Ellen MacArthur Foundation, 2018). Canada needs to lessen consumption and adopt zero-plastic waste strategies by reducing, reusing and recycling single-use plastics (Walker and Xanthos, 2018). Adoption of the circular economy and EPR systems will help reshape and rebalance current flow-through of waste volume. As a policy tool, EPR enables the producer of a product to be responsible after initial use and extended to the post-consumer stage of a product lifecycle (CCME, 2018; Diggle and Walker, 2020). Further understanding of export patterns of recyclable materials from developed to developing countries will help reduce waste pollution transfers (Liu et al., 2018; Walker, 2018). The aim of this study was to identify driving factors behind change in perception and anticipated behavior of consumers towards the consumption of single-use plastics in the Canadian food industry. Findings gathered from this study will help inform policy decisions by corporations, food packing manufacturers and government.

\section{Methods}

Consumers are becoming more concerned about food packaging waste (Charlebois et al., 2014). This study tackles current singleuse plastic packaging consumption patterns and production systems based traditional practices. Generally difficult to reach scale, commercial plastic packaging technologies are now challenged by contemporary market forces (Dües et al., 2013). Market-ready technologies and solutions are increasingly in demand and were explored in this survey as viable options to curb single-use plastic packaging waste derived from food products. This study used a survey methodology conducted through a formulated questionnaire within Canada (supplementary material S1). This method was appropriate to identify potential links between consumer willingness to pay for green packaging in food products and industrial approaches to curbing the single-use plastics predicament. Green packaging was assumed to include several board criteria, such as easily or readily recyclable, produced from natural raw materials with limited environmental consequences during production and end-of-life, or reusable materials. 


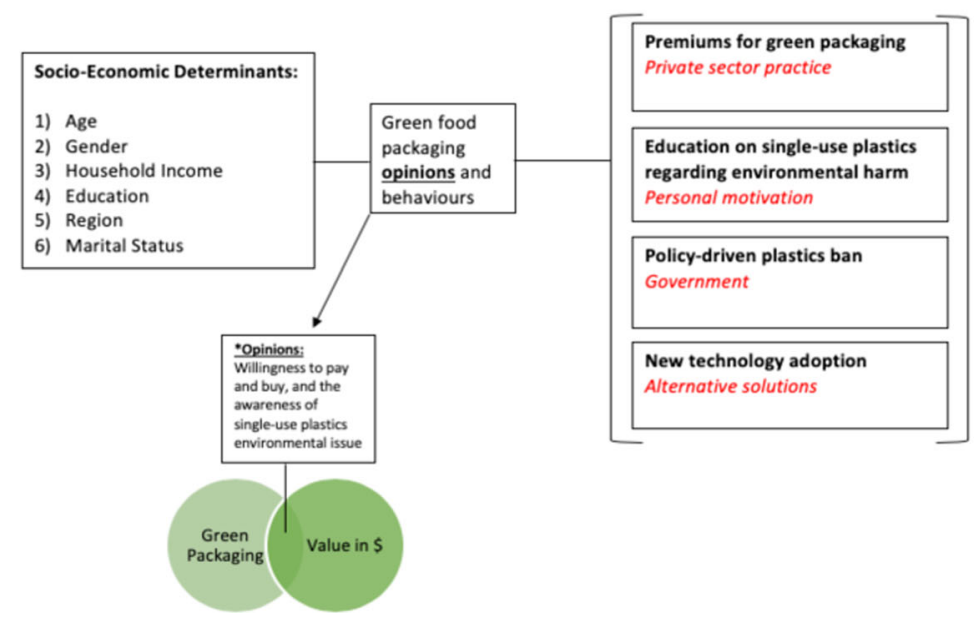

Fig. 1 Conceptual framework of single-use plastic use in the Canadian food sector.

To guide the study and understand repercussions in the Canadian food industry regarding market behavior around singleuse plastic packaging, a conceptual framework was developed to probe Canadian perceptions on possible solutions to reduce unnecessary or over-packaging in the food industry (Fig. 1). From this, a quantitative survey was developed using a series of statements and 5-point Likert scale (1 Strongly agree 2 Agree, 3 Neither disagree nor agree, 4 Disagree, 5 Strongly disagree) to measure both agreement and uncertainty, where "Strongly Agree" and "Agree" denote high motivation and "Neither Agree nor Disagree" denotes uncertainty. The survey was divided into four parts. First, the socio-economic determinants (age, gender, income, education, region and marital status) of respondents were collected. Second, the survey probed respondents whether their purchasing behavior was based on environmental awareness. Third, a serious of questions on responsibility for green food packaging was asked. Finally, willingness to adapt behavior was queried.

Data were collected through an online survey conducted across Canada through an online survey platform administered through a third-party fieldhouse, Qualtrics. The survey was available for seven days from May 10th through 17th of 2019 in French and English. Virtually all Canadians are exposed to food packaging, therefore, using the Qualtrics panel of over 1.3 million self-selecting Canadian consumers was appropriate. This panel has a sampling frame that covers $97 \%$ of the Canadian population of adults over the age of 18 . Survey results were weighted by age and gender in each region to correct for any sampling bias and non-response bias among difficult-to-reach populations. Based on the sampling design, the margin of error was $3.1 \%$ with a $95 \%$ confidence interval, which means that respondent data were within 3 percentage points of the real Canadian population value $95 \%$ of the time.

Once a pre-test of 50 completes determined that the survey instrument was sound, the survey was administered to 1112 randomly selected adult Canadians and achieved a response rate of $96 \%$. The survey took on average of $11 \mathrm{~min}$ to complete. Incomplete responses were removed as were those of respondents who answered in the survey in under $3 \mathrm{~min}$. This left 1014 valid responses. All respondents have lived in Canada for 12 months and are least 18 years of age drawn from the population across British Columbia, the Prairies, Ontario, Quebec, the Atlantic Provinces (New Brunswick, Nova Scotia, Prince Edward Island and Newfoundland and Labrador), and the North (Yukon, Northwest Territories, Nunavut). The regions within Canada used in this study were based on generally accepted subdivisions for the country, which have been used by other studies in their sampling designs (Beck et al., 2005; Hajizadeh et al., 2016; Naud et al., 2019).

Data analysis was completed using the SPSS version 25 . Though the fieldhouse, Qualtrics, set quotas within the survey platform based on Canadian census data of age and gender within region, there was a need to weight the data due to over sampling in some regions. As the survey is conducted in real time, quotas can overfill if many respondents start the survey in a contracted timeframe. As mentioned above, the data was cleaned after the survey finished in field, and any responses under $3 \mathrm{~min}$ were removed. Therefore, weights for the data were developed according to Statistics Canada Census Profile 2016 and applied to correct for any sampling deficiencies in age and gender within region at time of collection (Statistics Canada, 2019). This study was completed to provide context for future studies. As data were not normally distributed, ranked-based nonparametric tests were used to determine differences between groups. As such, differences in medians were measured with Kruskal-Wallis $\mathrm{H}$ tests to determine significance between subgroups, age (18-23 24-38, 39-53, 54-72, 73+), region (British Columbia, Prairies, Ontario, Quebec, Atlantic Provinces, North) income ( $<\$ 40,000, \$ 40,000-\$ 79,999, \$ 80,000-\$ 149,999$, $\$ 150,000+$ ) and education (high school diploma, undergraduate degree, college diploma, graduate degree or doctorate, other). A Mann-Whitney U-test was used to determine differences in scores by gender. Two-way analysis of variance (ANOVA) was used to determine the main effect of age and region and education and region on the perceptions of responsibility.

Limitations with self-reported survey data exist. Several studies discuss likelihood of aspirational perceptions of self-behaviors (Hartley et al., 2015; Pahl and Wyles, 2017; Wyles et al., 2019). Despite this, understanding consumers' perceptions of single-use plastics in the food industry provides insights into larger social implications for the Canadian food industry and for waste management of single-use plastic food packaging after use (Lindh et al., 2016). The understanding relies on empirical evidence regarding human decision-making and incentives that go beyond economic metrics (Jia et al., 2019).

\section{Results}

Socio-demographic characteristics. Socio-demographic profiles by Canadian region were reflected in weighted data (Table 1). 
Distribution of respondents by regions shows that most reside in Ontario (38.2\%), followed by Quebec (21.6\%), Prairies (Alberta, Saskatchewan and Manitoba) (18.8\%), British Columbia (13.5\%), Atlantic Provinces (7.6\%), and the North $(0.03 \%)$. There were slightly more females (55.5\%) than males (45.5\%). Most respondents were aged $54-72(32.7 \%)$, followed by $39-53(24.6 \%)$ $24-38(22.1 \%), 18-23(12.1 \%)$ and $73+(8.5 \%)$. Most respondents had attained a high school or college diploma $(32.5 \%$ and $31 \%$, respectively.

Consumer behavior and opinions. Kruskal-Wallis $\mathrm{H}$ tests were run to determine if there were differences in motivation among independent variables (age, region, income, and education). Examples are shown in Table 2. For example, for the survey question: I am personally motivated to reduce the amount of single-use plastic food packaging because of its environmental impacts, most respondents, $88.9 \%$, answered "Strongly agree" or "Agree" on the 5-point Likert scale. Figure 2 and Table 2 show participant responses related to motivation to reduce consumption by region, income, education, and age. Distributions of motivations scores were similar for all age groups. Median

\begin{tabular}{|lc|}
\hline \multicolumn{2}{|l|}{ Table 1 Socio-demographic characteristics of respondents. } \\
\hline Socio-demographics & Percent \\
\hline Sex & \\
Male & 45.5 \\
Female & 55.5 \\
Region & \\
Ontario & 38.2 \\
Quebec & 21.6 \\
Prairies & 18.8 \\
British Columbia & 13.5 \\
Atlantic Provinces & 7.6 \\
North & 0.03 \\
Age (years) & \\
18-23 & 12.1 \\
24-38 & 22.1 \\
39-53 & 24.6 \\
$54-72$ & 32.7 \\
Z73 & 8.5 \\
Education groups & \\
High school diploma & 32.5 \\
Undergraduate degree & 16.5 \\
College diploma & 31.0 \\
Graduate or doctorate degree & 9.8 \\
Other & 10.2 \\
\hline
\end{tabular}

motivation scores were not statistically significantly different between age groups, $\chi^{2}(4)=4.598, p=0.331$. Distributions for motivation were not similar for income or education. Median motivation scores were not statistically significantly different between income groups, $\chi^{2}(4)=5.059, p=0.168$, or education groups, $\chi^{2}(4)=8.850, p=0.065$, respectively. However, the Kruskal-Wallis test, to determine if there were differences in motivation scores between regions, British Columbia $(n=142)$, Prairies $(n=201)$, Ontario $(n=405)$, Quebec $(n=231)$, Atlantic Provinces $(n=81)$, and North $(n=3)$, was statistically significant (Fig. 2). Distributions of motivation scores were not similar for all groups. Motivation scores were statistically significantly different between different regional groups, $\chi^{2}(4)=19.989, p=0.001$. Subsequently, pairwise comparisons were performed using Dunn's (1964) procedure with a Bonferroni correction for multiple comparisons (supplementary material S2). Adjusted $p$-values are presented. This post hoc analysis revealed statistically significant differences in median motivation scores between Quebec (480.13) and the Prairies (571.36) $(p=0.001)$, and Ontario (502.77) and the Prairies (571.36) $(p=0.012)$, but not between other group combinations. A Mann-Whitney $U$-test was used to determine if there were differences in motivation scores between males and females. Distributions of motivation scores for males and females were similar. Median motivation score was not statistically significantly different between males and females, $U=125,216.5, z=-1.271, p=0.204$, using an exact sampling distribution for $U$ (Dineen and Blakesley, 1973).

Influence on consumer change and adaptation. Many driving forces influence consumer behavior and opinions around singleuse plastic packaging. Moreover, the same forces influence change and adaptation. Taking into consideration the four main pillars of driving forces on consumers indicated in the conceptual framework (Fig. 1) (industry, government, personal motivation, and sustainable technologies), $91.1 \%$ of respondents believe that regulations to reduce consumption of single-use plastic food packaging should be strengthened in Canada. Older respondents were more likely to believe that regulations need to be more robust. Additionally, $74.3 \%$ of respondents were in favor of receiving a discount, incentive or rebate for supporting alternative plastic packaging solutions at purchase point. Higher educated respondents were less likely to prefer discounts or incentives if more bans continue to unfold in the marketplace.

Effect of age and region on robustness of regulations was investigated by a two-way ANOVA. Residual analysis was performed to test for assumptions of the two-way ANOVA. There were outliers present, as assessed as being greater than 1

Table 2 Consumer behavioral traits towards single-use plastic packaging.

\begin{tabular}{|c|c|c|}
\hline Behavior & $\chi^{2}(\rho$-value $)$ & Dunn's post hoc with Bonferroni correction \\
\hline Age & $4.598(0.331)$ & \\
\hline Income & $5.059(0.168)$ & \\
\hline \multirow[t]{2}{*}{ Region } & $19.989(0.001)$ & Quebec (480.13) vs. Prairies (571.36) $(p=0.001)$ \\
\hline & & Ontario (502.77) vs. Prairies (571.36) $(p=0.012)$ \\
\hline \multicolumn{3}{|c|}{ I am willing to pay more for an item containing bio-degradable packaging } \\
\hline \multicolumn{3}{|c|}{ I support a ban of all single-use plastics used for food packaging } \\
\hline Region & $17.553(0.002)$ & $\begin{array}{l}\text { British Columbia (464.62) vs. Prairies }(566.86)(p=0.001) \\
\text { Ontario (488.55) vs. Prairies }(566.86)(p=0.005)\end{array}$ \\
\hline
\end{tabular}


(a) Region

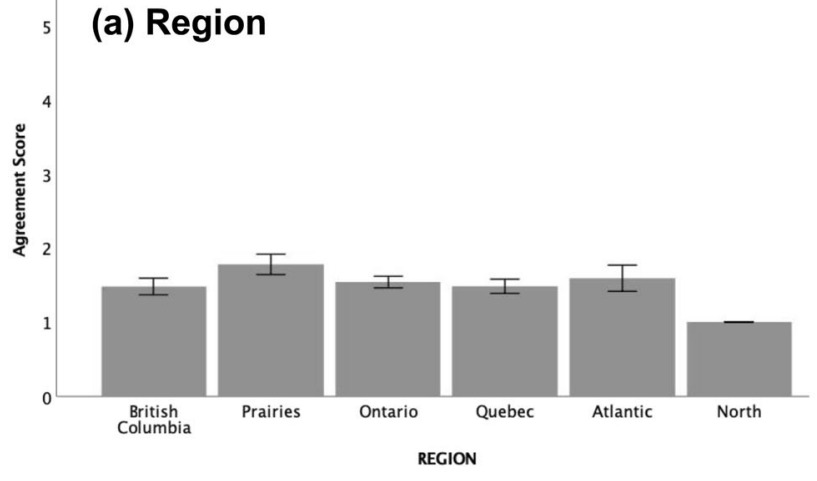

(c) Education level

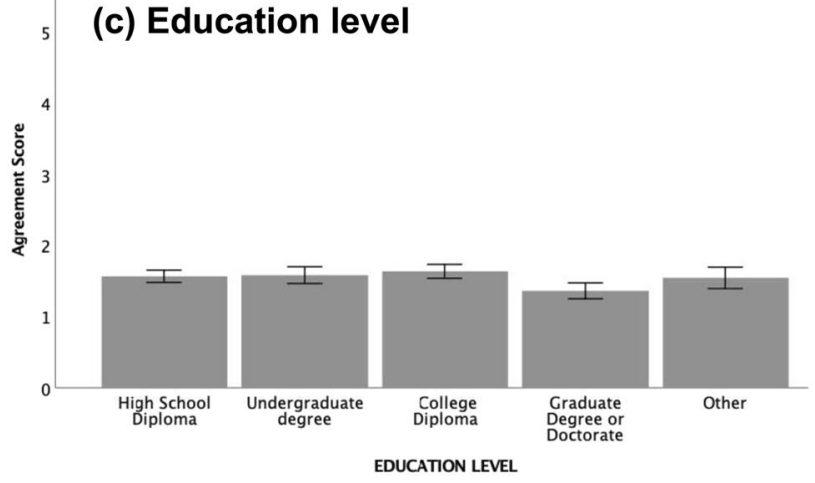

(b) Income
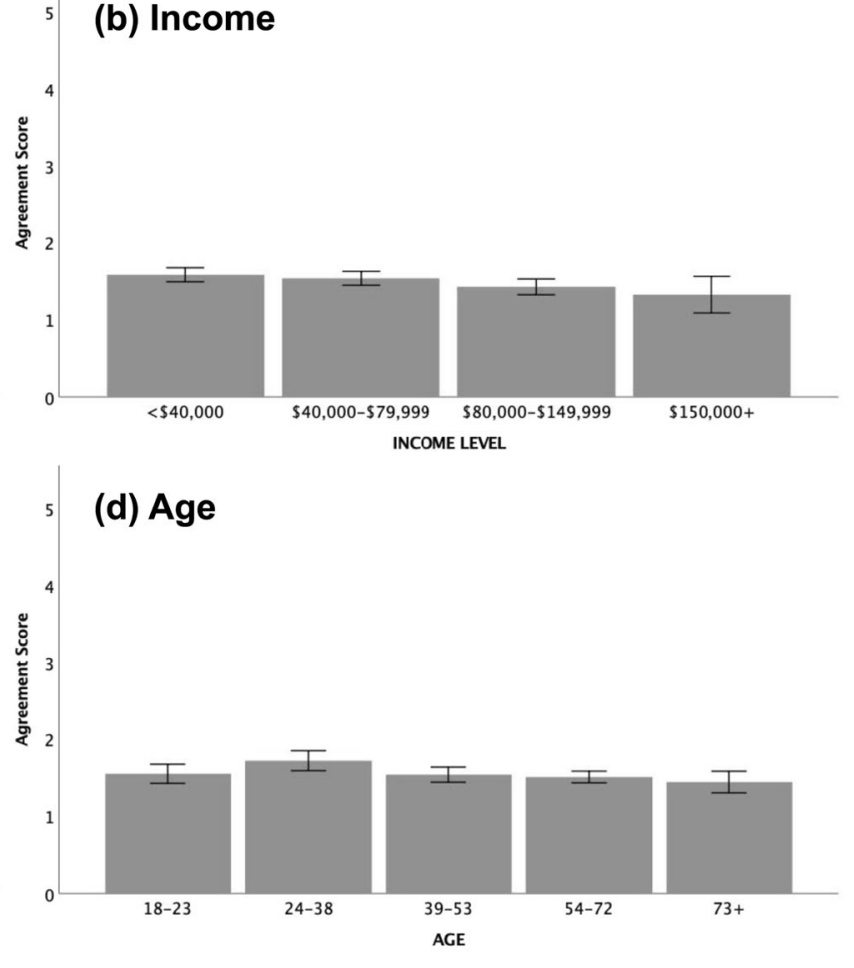

Fig. 2 Consumer motivation to reduce the amount of single-use plastic food packaging by region, income, education level, and age. Panels indicate region (a), income (b), education level (c), and age (d). Error bars indicate standard deviation.

box-length from the edge of the box in a histogram for each variable at both the upper and lower end. Given the nature of population distribution of respondents, this was unsurprising. Rather than removing data points, outliers were left in the dataset. Data was not normally distributed, as assessed by Shapiro-Wilk's test $(p<0.05)$. The assumption of homogeneity of variances was violated, as assessed by Levene's test for equality of variances, $p=3.5354 \mathrm{E}-16$. The interaction effect between age and region on the need for increased regulations was statistically significant, $F$ $(13,987)=3.393, p=0.000039$, partial $\eta^{2}=0.043$.

The effect of education and region on the need for incentives was investigated by a two-way ANOVA. Residual analysis was performed to test for the assumptions of the two-way ANOVA. There were outliers present, as assessed as being greater than 1 box-lengths from the edge of the box in a histogram for each variable at both the upper and lower end. Outliers were left in the dataset. Data was not normally distributed, as assessed by Shapiro-Wilk's test $(p<0.05)$. The assumption of homogeneity of variances was violated, as assessed by Levene's test for equality of variances, $p=0.000002$. The interaction effect between education and region on the need for increased regulations was statistically significant, $F(12,988)=2.239, p=0.009$, partial $\eta^{2}=0.026$. All pairwise comparisons were run where reported $95 \%$ confidence intervals and $p$-values are Bonferroni-adjusted.

Solutions. The path to a zero-plastic waste future will not be easy. Possible solutions based on survey responses consists of a mixture between biodegradable product opportunities and commercialization, retail pricing, government bans and taxes, and corporate social responsibility (CSR) tactics from industry participants. Across Canada, $41.9 \%$ of respondents were willing to pay more for items containing biodegradable packaging (Fig. 3). Younger respondents were more likely to pay more for biodegradable packaging. A Kruskal-Wallis test was conducted to determine if there were differences in willingness to pay scores between age groups $18-23(n=114) 24-38(n=234), 39-53(n=258), 54-72$ $(n=351), 73+(n=90)$, was statistically significant. Distributions of scores were similar for all groups. Willingness to pay scores were statistically significantly different between different age groups, $\chi^{2}(4=24.193, p=0.00001)$. Subsequently, pairwise comparisons were performed using Dunn's (1964) procedure with a Bonferroni correction for multiple comparisons (supplementary material S3). Adjusted p-values are presented. Analysis revealed statistically significant differences in median willingness to pay scores between age group 18-23 (398.59) and age group 24-38 (524.78) $(p=0.002)$, group 18-23 (398.59) and age group $73+(532.19)(p=0.012)$, and group 18-23 (398.59) and age group 54-72 (538.11) $(p=0.000)$ but not between other group combinations.

For a government tax to disincentivize consumption of singleuse plastic food packaging, 33.3\% of respondents were in favor. Higher educated respondents were more likely to accept paying a sales tax (Fig. 4). A Kruskal-Wallis test conducted to determine if there were differences in tax acceptance scores between education groups high-school diploma $(n=341)$, undergraduate degree $(n=173)$, college diploma $(n=326)$, graduate degree or doctorate $(n=102)$, and other $(n=107)$. However, results showed no statistical difference between groups.

At the forefront of government policy, a ban on all single-use plastics used for food packaging was supported by $73.4 \%$ of respondents (Fig. 5). Significance testing conducted to determine if there were differences on total ban support scores between regions, British Columbia, Prairies, Ontario, Quebec, Atlantic Provinces, and North, showed significances. Distributions of ban support scores were not similar for all groups, as assessed by visual inspection of a histogram. Motivation scores were statistically significantly different between different regional groups, $\chi^{2}(4)=17.553, p=0.002$. Adjusted $p$-values are present 


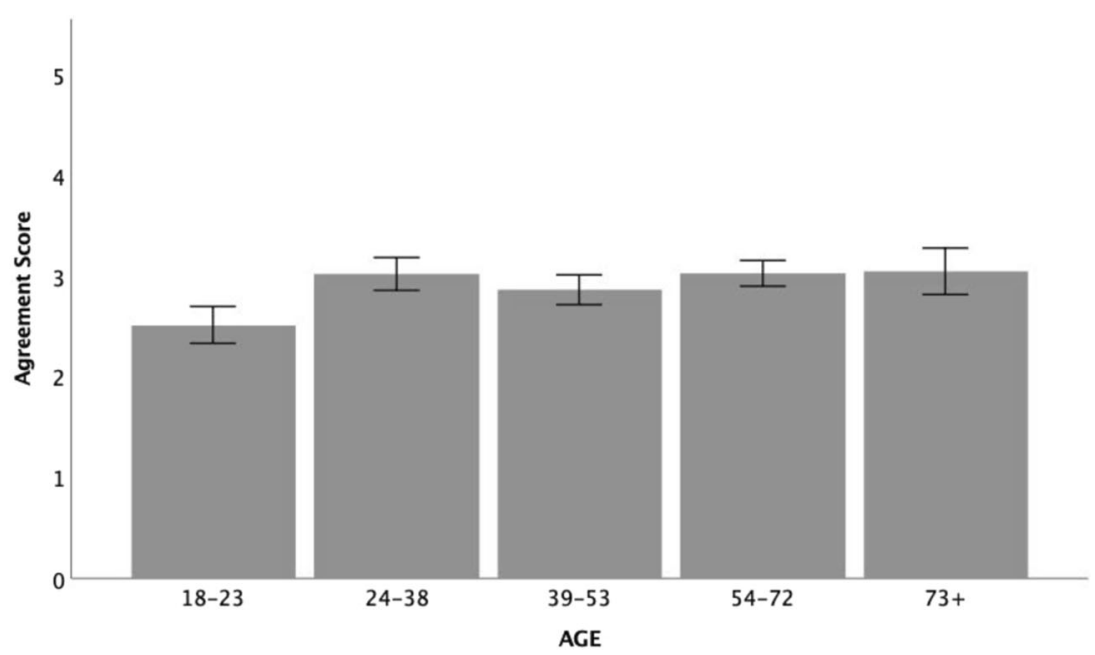

Fig. 3 Consumer willingness to pay a higher price for biodegradable packaging by age. Error bars indicate standard deviation.

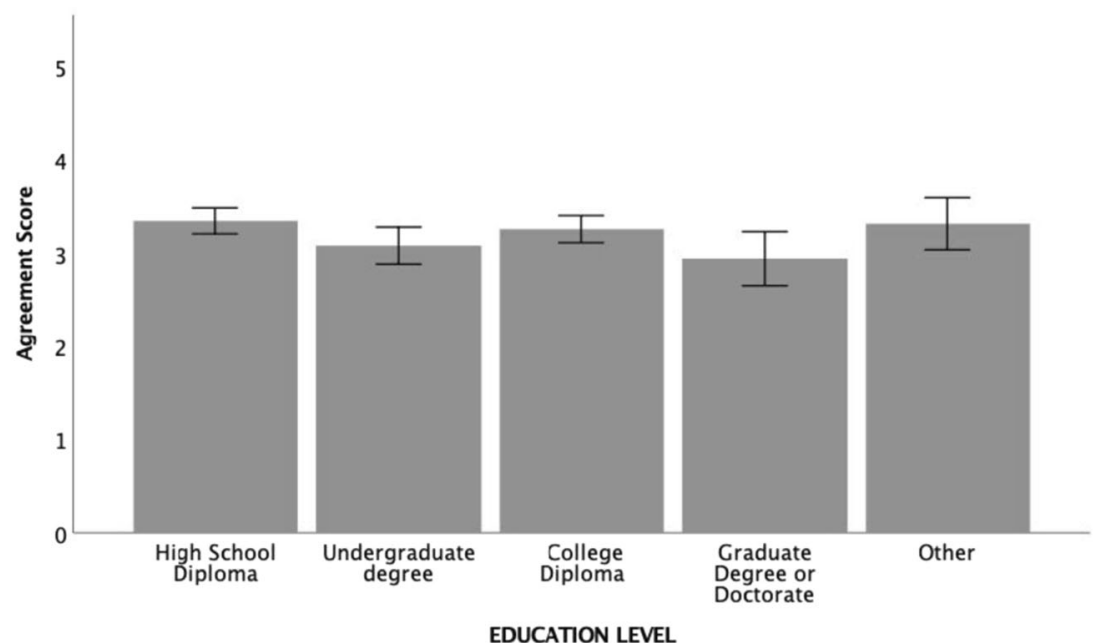

Fig. 4 Consumer acceptance to pay government tax by education level. Error bars indicate standard deviation.

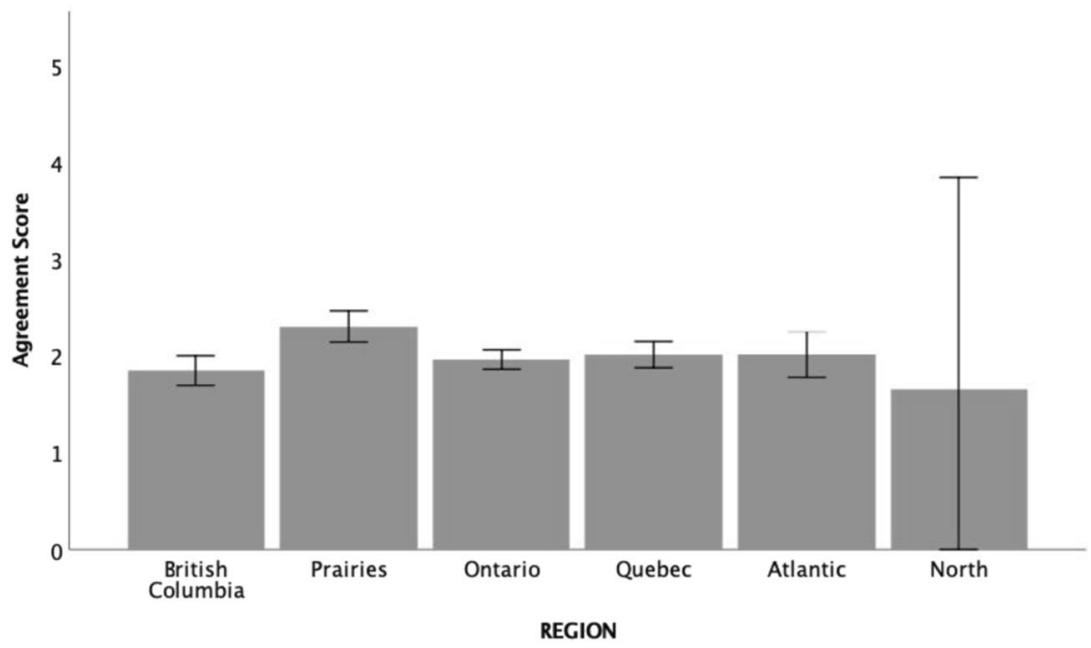

Fig. 5 Consumer support for ban on all single-use plastics used for food packaging by region. Error bars indicate standard deviation. 


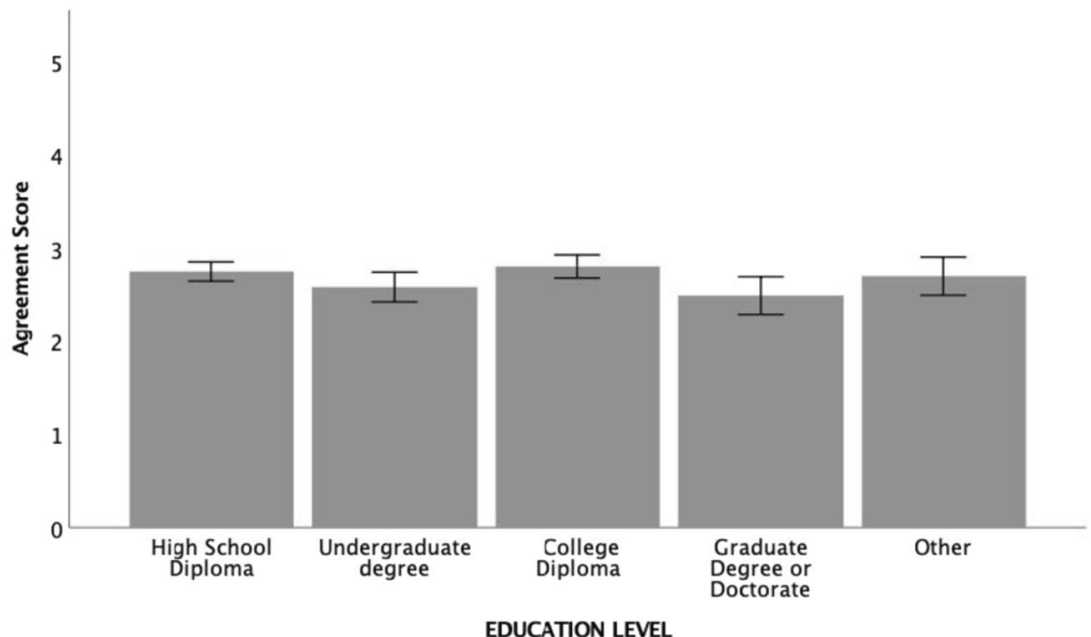

EDUCATION LEVEL

Fig. 6 Consumer level of understanding of branding and marketing of eco-friendly (sustainable) packaging by education level. Error bars indicate standard deviation.

in pairwise comparisons. Statistically significant differences in median ban support scores were present between British Columbia (464.62) and the Prairies (566.86) $(p=0.005)$, and Ontario (488.55) and the Prairies (566.86) $(p=0.005)$, but not between other group combinations (supplementary material S4).

Complementary findings. Of the four driving pillars behind consumer behavior and influence on change, new product opportunities and technology adoption in the marketplace showed some confusion at the consumer level (Fig. 6). Up to $44.1 \%$ of respondents suggested they were confused with branding and marketing of sustainable single-use plastic food packaging. There was no significant difference among education groups on the level of confusion with branding of single-use plastics $(p=0.054)$. To reduce single-use plastic consumption at the food level, $90.6 \%$ of respondents believed they should be further educated on recycling processes, plastic use, and overall environmental impacts. There was no significant difference among education groups on the need for further education $(p=0.141)$. Neither were there significant differences among income groups $\chi^{2}(4)=7.665 p=0.053$, nor regional differences $(p=0.145)$. Roughly three quarters $(76.1 \%)$ of respondents believed media coverage and pressure on the food industry was an efficient single-use plastic food packaging reduction strategy. There were no significant differences among demographic groups age $(p=0.54)$, gender $(p=0.564)$, region $(p=0.290)$, education $(p=0.858)$ and income $(p=0.789)$.

\section{Discussion}

A dominant factor identified early in the research was the Canadian population's perception of single-use plastics. In recent years, awareness and understanding has grown rapidly but remains fragmented amongst regions, household income and education levels (Deloitte and Environment and Climate Change Canada (ECCC), 2019). Consumers in Canada tend to respond to market forces as they relate to environmental issues but also have been criticized to have shown patterns of strong ties between convenience and food products. That same convenience was linked to the single-use plastic packaging issue faced in the Canadian food industry: consumers want selection and variety, but plastic packaging provides product safety and longevity. Furthermore, the Canadian federal government announced bans on certain single-use plastics by 2021 and many of the banned items will be single-use food related packaging such as straws, lids and wrappers (Walker, 2019). Among the countries around the world pledging to reduce plastic waste, Canada announced in would "ban harmful single-use plastics" in 2019 (Government of Canada, 2019). As of 2018, 127 countries had implemented some legislative measures targeting single-use plastics. Since then, some jurisdictions have reversed or paused their measures due to pressure from plastic lobbyists, citing the COVID-19 pandemic as the cause for reversal (Prata et al., 2020; Silva et al., 2020, 2021; Walker, 2020).

However, Canada is still committed to banning single-use plastics. Under a newly unveiled list of single-use plastics being banned in Canada (announced on October 72020 ), plastic grocery bags, straws, stir sticks, six-pack rings, cutlery and food containers made from hard-to-recycle plastics will be banned nationwide by the end of 2021 (Environment and Climate Change Canada and Health Canada, 2020; Government of Canada, 2020). Canada is banning harmful single-use plastic items (i.e., where there is evidence that they are found in the environment), under Schedule 1 of the Canadian Environmental Protection Act, 1999 (CEPA). This regulatory step using CEPA is one of Canada's principal laws for preventing pollution and protecting the environment (Government of Canada, 2020). Provincial governments, particularly in eastern Canada, have also announced legislation banning singleuse plastics. The Plastic Bag Reduction Act in Prince Edward Island came into effect July 12019 (Government of Prince Edward Island, 2020), followed by the retail plastic bag ban in Newfoundland and Labrador to come into effect original on July 1 2020, but due to the COVID-19 pandemic was paused (CTV News Atlantic, 2020). The Plastic Bags Reduction Act (Bill 152) in Nova Scotia takes effect on October 302020 (Government of Nova Scotia, 2019). Cities in Canada, such as Montreal and Vancouver, respectively also made progress banning single-use plastic items in 2018 (Marchildon, 2019).

For the Canadian food sector, the idea of convenience resonates with consumers and plastic has enabled retailers and manufacturers to meet this demand. The ability to increase variety and shelf life of food products in Canada is also directly correlated with plastic evolution and rapid growth seen in the last century of consumption and production (Deloitte and Environment and Climate Change Canada (ECCC), 2019). As consumers, policymakers, industry representatives and subject-matter experts debate the future of single-use plastics in food packaging, the implementation of market instruments and policies lags largely 

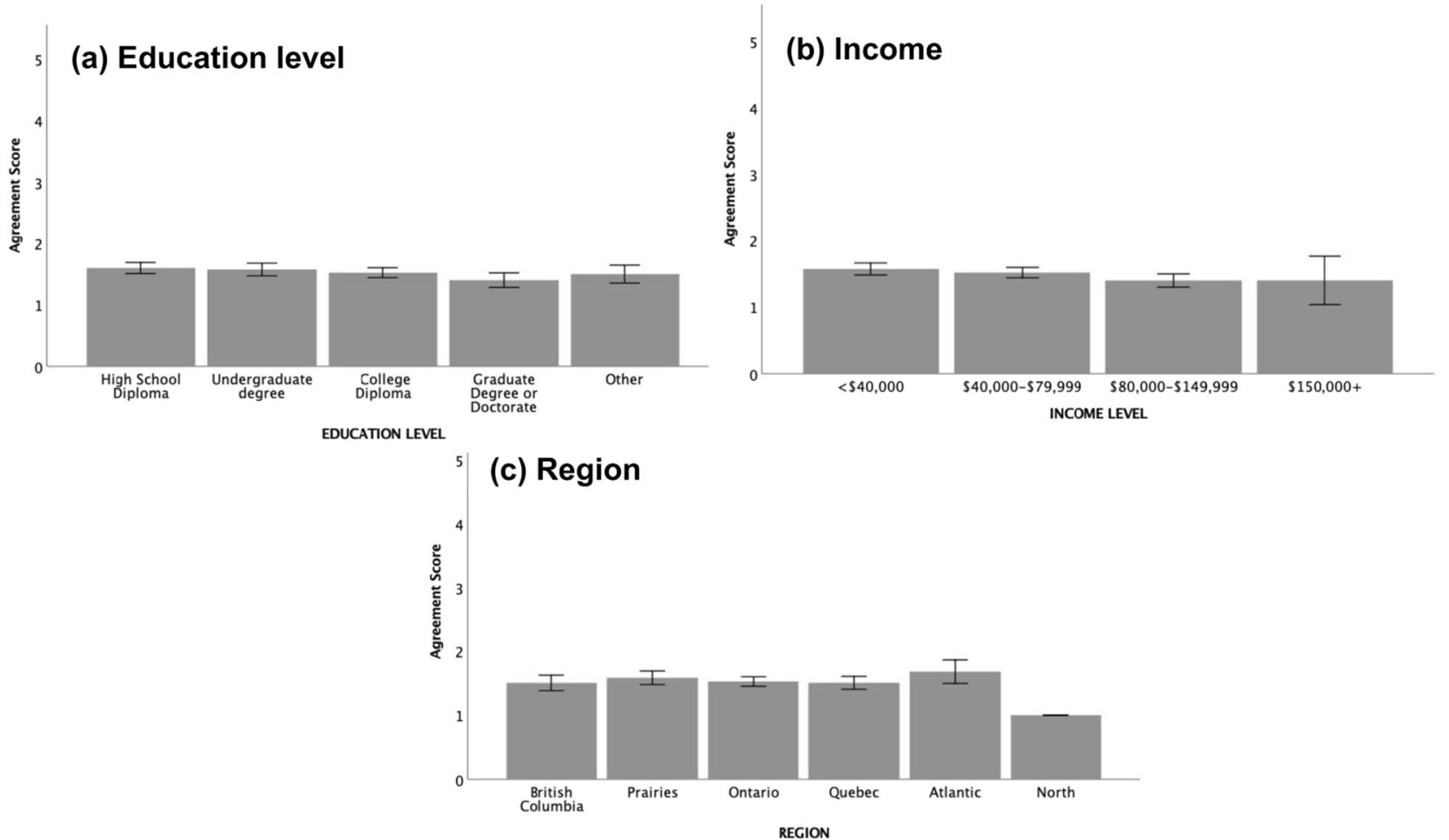

Fig. 7 Consumer opinion on further education needed to reduce single-use plastic consumption by education, income, and region. Panels indicate education (a), income (b), and region (c). Error bars indicate standard deviation.

because of top-down approaches that have been taken (Xanthos and Walker, 2017). These approaches lack social and environmental indicators supporting market-based policy and public participation (Schnurr et al., 2018).

To better understand Canadian consumers' perspectives, the industry must address what consumers are demanding: clearer and better understanding of plastic waste management, recycling processes, and availability of biodegradable and compostable options (Herbes et al., 2018). However, biodegradable food packaging options are not always better than alternatives if they cannot be handled by municipal solid waste facilities due to potential risks with breakdown of microplastics (Dilkes-Hoffman et al., 2018; Environment and Climate Change Canada and Health Canada, 2020; Government of Canada, 2020). Without new management strategies, current recycling rates will not be increased and ambitious goals and timelines to a zero-plastic waste future in Canada will be insurmountable (Walker and Xanthos, 2018; Karbalaei et al., 2018, 2019, 2021; Environment and Climate Change Canada and Health Canada, 2020). The duo between recycling infrastructure and the redesign of plastic packaging and products to retain value and increase reuse can help support the framework for knowledge sharing and promoting proper management of plastic waste, including harmonization of technical standards and practices (Hanss and Böhm, 2012). In essence, this can help build capacity to properly manage the single-use plastic waste derived from food products in Canada.

Food companies such as processors, distributors and retailers may seek to communicate their environmental performance to outside stakeholders but may not always find this easy to do since they may lack full knowledge of processes, and material flowing through supply chains through to customers. Furthermore, food retailers and plastic manufacturers may increase visibility into plastic inputs in food packaging, but to convey to the broader public that improved packaging solutions are readily available in the marketplace remains a challenge. The inability for consumers to distinguish between mainstream and green food packaging is difficult to address and information sharing is critical for coordinating supply chain dynamics (Fig. 7). Over the course of the last year, Canadian retailers and major food companies have made improvements and taken leadership positions to reduce single-use plastics in food packaging and banning plastic grocery bags. Major retailers in Canada such as Loblaws, Metro, Sobeys and Walmart have all stated respective plans and initiatives to curb plastic waste from their operations in 2020 (Sagan, 2019). In response to consumer demands and government regulations, momentum is building across industry leaders and the opportunity to harness marketplace shifts. Although some announcements came after this national study, they remain relevant as many of these discussions were happening in the media, municipal council meetings and Canadian Council of Ministers of the Environment (CCME) sessions before findings were released.

Gaps and challenges in Canada. Results of this study cannot be generalized across the entire economic system because of the nature of packaging requirements in the food industry compared to electronics, auto-parts, textiles, building and construction, healthcare, and broader agricultural products. In short, the definition of "single-use" needs to be unpacked as it may be possible to explore options of readily available reuse items in today's marketplace. In an industry forced with tight margins, highturnover inventory and perishability risks, less change may seem like a logical step where partnerships across the supply chain should not be disrupted. To get to the intended future state levels of prevention and management of single-use plastic packaging, the upstream and downstream relationships need to be improved in the marketplace. Although this study on single-use plastics use can be applied in other jurisdictions, the Canadian market was the primary focus for this research. In Canada, there is currently a lack of sufficient infrastructure to manage plastic waste or plastic 
recycling. Development of a series of standards, in addition to new processes for value creation of plastic waste, will provide a major economic opportunity for Canada going forward.

Producing food requires many inputs; land, water, fertilizer and energy. Even more, using these finite resources in Canada makes it harder for consumers to accept, especially when perception includes both unacceptable food waste levels and the unknown of plastic waste derived from single-use plastic food packaging. Similar to Europe, this paper finds that Canada must assess how the growth in plastic packaging waste generation over time has witnessed coinciding increases with food waste. For instance, a time series of domestic plastic packaging and food waste in Canada, such as in the Plastics Europe review (2017), is required to demonstrate the simultaneous movement in waste figures between both categories as they are proven not to be mutually exclusive. Identifying and synthesizing dispersed data on production, use, and end-life management of single-use plastics in food packaging presents a unique opportunity for Canada. Geyer et al. (2017) found that if current production trends hold constant, by 2050, 12 billion MT of plastic waste will end up in landfills. This study demonstrates how driving factors impact consumer behaviors and perceptions surrounding singleuse plastic packaging in food. Analysis and methodology applied suggests that regardless of steps taken to manage the issue going forward in Canada, complexities along the entire food supply chain are long-term (Charlebois et al., 2014).

Although research outlining environmental, social and economic impacts of plastic pollution is growing, few studies have examined policy and legislative tools to reduce plastic pollution, particularly single-use plastics (Xanthos and Walker, 2017). Furthermore, policies at the global scale for reduction of singleuse plastics lack the ability to document or measure their effectiveness (Schnurr et al., 2018). There is a growing need for an integrated approach to assessing plastic waste generated by Canadians from single-use plastic food packaging. In Canada, most plastic waste is derived from single-use plastic food packaging, but better assessments should consider more waste management scenarios, which often ignore environmental leakage of packaging (Srivastava, 2007). A broad frame of reference for single-use food packaging is not adequately developed, and the Canadian contribution to the issue is not insignificant. In fact, public opinion towards single-use plastics seems to be derived directly from major environmental repercussions (Walker and Xanthos, 2018). Production and consumption of more sustainable products is an important step towards achieving higher sustainability targets through less waste and through packaging containing alternative materials (Ertz et al., 2017). Further, assessing plastic waste from single-use plastic food packaging must be considered through the lens of raw material use, production processes, and waste management before making recommendations around sustainable packaging alternatives (Molina-Besch et al., 2019).

CSR, a result of pressure from customers to improve environmental performance, is a major response to the singleuse plastics issue in food packaging (Weinhofer and Hoffmann, 2010). When firms downstream in the supply chain seek to achieve environmental improvements, they attempt to complete this step by pressuring upstream suppliers also adopt greener practices. Evidence of the systematic approach where stages of the supply chain start to rely on one another for environmental performance can be characterized as signals towards incentives, but effectiveness varies entirely on relationships between suppliers and customers (Delmas and Montiel, 2009).

Consumer pressure on stages of the supply chain producing and using single-use plastics is a driving force behind adoption of new standards and services (Garnett, 2011). However, few studies analyze how the relationship between industrial customers and suppliers influence adoption (Delmas and Montiel, 2009). Therefore, there remains a knowledge gap and understanding around the issue of tailoring to new consumer demands. A positive perception of a packaged product, however, does not automatically mean a person will purchase it, since many factors are considered in a buying decision. The lack of knowledge around sustainable consumer behavior is considered a "attitudebehavior gap" where many consumers' positive attitude and noble intentions to act in a sustainable way are not translated into actual consumer behavior (Scott and Vigar-Ellis, 2014; Ketelsen et al., 2020). Lastly, corporate approaches in Canada to overcome consumer demand changes need to include continuous technological advancements. The notion of green product development must adhere to strong social, economic and technological fundamentals, while following strict and swift adaptation to consumer changes (Rokka and Uusitalo, 2008; Arboretti and Bordignon, 2016). Although change can be difficult for corporate strategy, it can present new business opportunities (Bowen and Aragon-Correa, 2014). This can create competitive advantage if Canada's food industry can seek a better understanding of the consumers' willingness to pay a premium for green (sustainable) packaging for food products (Rokka and Uusitalo, 2008).

Possible implications. In Canada, plastics remaining in the packaging system need to be simplified and standardized; fewer polymers, pre-vetted material inputs, less additives and easier recycling capacity (Prata et al., 2019). Across the supply chain, the use of compostable packaging and value-retention with single-use plastics should be encouraged and incentivized. To achieve this target, policymakers should address regulatory hurdles to enhance and support industrial research and commercialization opportunities of compostable packaging, which includes and involves municipalities. Furthermore, industry should be encouraged to adopt a circular economy model in line with the federal government's zero-plastic waste strategy (CCME, 2018).

Globally, capturing material value in the new plastics economy requires a disciplined approach. According to the Ellen MacArthur Foundation (2018), the plastics industry could be saved by retaining and capture value of waste. In Canada, over half of all disposable plastic products, many of which are derived from the food industry, are used once and thrown away. Most plastic types contribute to approximately CAD $\$ 35$ billion in annual sales and over $5 \%$ of the plastics manufacturing sector in Canada is linked to plastic resin production (Deloitte and Environment and Climate Change Canada (ECCC), 2019). The lifecycle of plastics is linear in nature and packaging consists of $43 \%$ of the main waste generators in Canada. Plastic materials, more specifically single-use packaging, that are not recovered represents a lost opportunity of CAD $\$ 7.8$ billion for Canada in 2016 and the outlook to 2030 estimates unrecovered plastics lost value could rise to CAD $\$ 11.1$ billion (Deloitte and Environment and Climate Change Canada (ECCC), 2019).

Extending plastics lifetime to reduce and delay waste generation is a major component in supporting a transition towards a zeroplastic waste future. Finding secondary markets is critical and can overcome barriers such as plastics recovery policies and regulations, process losses and the absence of high-volume recovery options. Holding both producers and retailers accountable for making sure that material used is properly managed by the consumer should be enforced through strict liability. Achieving goals established by the food industry leaders and responding to demands from consumers will require a cohesive and comprehensive approach. Most importantly, Canada needs better alignment between food safety regulations and the agri-food sector's environmental obligations at all levels of government. 


\begin{abstract}
Alternative solutions to consider. Advancements in technology, academic research, policymaking and consumer insights allow for new perspectives to develop. Pursuit of a zero single-use plastic future in Canada must not over-look negative impacts of singleuse plastic food packaging used in the food industry, but the food industry needs concrete, measured, and realistic alternative solutions to deploy in the marketplace. As consumer perceptions of single-use plastic packaging informs policymakers and businesspeople, a broad-range of solutions are attainable to improve market dynamics. Moreover, fundamental public-private partnerships should be established to attract investments in research and development with the aim of rapidly scaling commercial solutions for single-use plastic food packaging.
\end{abstract}

\section{Conclusions}

Canadian consumers are highly motivated to reduce single-use plastic food packaging, but less willing to pay for alternatives. Addressing issues of single-use plastic pollution in Canada, including plastic food packaging, requires a holistic view and a well-orchestrated effort. Specific actions are required beyond legislation and policy-driven changes. Canada needs to consider food waste prevention techniques while striving to identify costeffective alternative materials to single-use plastic packaging to achieve zero-plastic waste, and drive consumer behavior change. Actions from all stakeholders including EPR, partnerships with cutting-edge alternative packaging suppliers, waste prevention initiatives, circular economy systems integration, education at the consumer level, and performance measures are all essential to overcome future environmental risks of single-use plastic packaging waste. Responses to single-use plastic waste derived from food packaging while striving for zero-plastic waste to reduce environmental impacts of plastic pollution is an integral part to Canada's commitment to create shared value for the food industry, society and government-driven plans. Accelerating action to tackle the issue of the food industry's contribution to single-use plastic packaging waste is imperative from all participants of the economic system.

\section{Data availability}

Data will be made available upon request

\section{Code availability}

Not applicable

Received: 23 July 2020; Accepted: 26 January 2021; Published online: 17 March 2021

\section{References}

Adam I, Walker TR, Bezerra JC et al. (2020) Policies to reduce single-use plastic marine pollution in West Africa. Mar Pol 116:103928

Arboretti R, Bordignon P (2016) Consumer preferences in food packaging: CUB models and conjoint analysis. Br Food J 118(3):527-540

Avery-Gomm S, Walker TR, Mallory ML et al. (2019) There is nothing convenient about plastic pollution. Rejoinder to Stafford and Jones viewpoint-ocean plastic pollution: a convenient but distracting truth? Mar Pol 106:103552

Beck CA, Metz LM, Svenson LW et al. (2005) Regional variation of multiple sclerosis prevalence in Canada. Mult Scler J 11(5):516-519

Bezerra JC, Walker TR, Clayton CA et al. (2021) Single-use plastic bag policies in the Southern African Development Community. Environ Chall 100029. https://doi.org/10.1016/j.envc.2021.100029

Bowen F, Aragon-Correa J (2014) Greenwashing in corporate environmentalism research and practice: the importance of what we say and do. Organ Environ 27(2):107

Brooks AL, Wang S, Jambeck JR (2018) The Chinese import ban and its impact on global plastic waste trade. Sci Adv 4(6):eaat0131
Canadian Council of Ministers of the Environment (CCME) (2018) Strategy on Zero Plastic Waste. https://www.ccme.ca/files/Resources/waste/plastics/1289 CCME \%20Canada-wide\%20Action\%20Plan\%20on\%20Zero\%20Plastic\%20Waste_ EN_June\%2027-19.pdf. Accessed 15 Sep 2020

Charlebois S, Stern RH, Buhr M (2014) Sharing and preparing: cross-institutional, food security-based knowledge in Canada. Int J Sust Dev World Ecol 21(6):1-8

Clayton CA, Walker TR, Bezerra JC et al. (2020) Policy responses to reduce singleuse plastic marine pollution in the Caribbean. Mar Pollut Bull 111833. https://doi.org/10.1016/j.marpolbul.2020.111833

CTV News Atlantic (2020) Retail plastic bag ban in Newfoundland and Labrador to come into effect July 1. https://atlantic.ctvnews.ca/retail-plastic-bag-banin-newfoundland-and-labrador-to-come-into-effect-july-1-1.4788475. Accessed 15 Sep 2020

Delmas M, Montiel I (2009) Greening the supply chain: when is customer pressure effective? J Econ Manage Strategy 18(1):171-201

Deloitte and Environment and Climate Change Canada (ECCC) (2019) Economic study of the Canadian plastic industry, markets and waste. Gatineau, Quebec http://publications.gc.ca/collections/collection_2019/eccc/En4-366-1-2019eng.pdf. Accessed 15 Sep 2020

Diggle A, Walker TR (2020) Implementation of harmonized extended producer responsibility strategies to incentivize recovery of single-use plastic packaging waste in Canada. Waste Manage 110:20-23

Dilkes-Hoffman L, Lane JL, Grant T et al. (2018) Environmental impact of biodegradable food packaging when considering food waste. J Clean Prod 180:325-334

Dineen LC, Blakesley BC (1973) Algorithm AS 62: a generator for the sampling distribution of the Mann- Whitney U Statistic. J R Stat Soc 22: 269-273

Dunn OJ (1964) Multiple comparisons using rank sums. Technometrics 6 (3):241-252

Dües CM, Tan KH, Lim M (2013) Green as the new lean: how to use lean practices as a catalyst to greening your supply chain. J Clean Prod 40:93-100

Environment and Climate Change Canada and Health Canada (ECCC) (2020) Science assessment of plastic pollution. Cat. No.: En14-424/2020E-PDF. ISBN 978-0-660-35897-0. Retrieved from. https://www.canada.ca/en/environmentclimate-change/services/evaluating-existing-substances/science-assessmentplastic-pollution.html. Accessed 15 Sep 2020

Ellen MacArthur Foundation, ARUP, McKinsey and Company, and UNCTAD (2018) The Circular Economy Opportunity for Urban and Industrial Innovation in China. https://www.ellenmacarthurfoundation.org/assets/downloads/ The-circular-economy-opportunity-for-urban-industrial-innovation-inChina_19-9-18_1.pdf. Accessed 15 Sep 2020

Ertz M, François J, Durif F (2017) How consumers react to environmental information: an experimental study. J Int Consum Marketing 29(3):162-178

Fernqvist F, Olsson A, Spendrup S (2015) What's in it for me? food packaging and consumer responses, a focus group study. Br Food J 117(3):1122-1135

Garnett T (2011) Where are the best opportunities for reducing greenhouse gas emissions in the food system (including the food chain)? Food Pol 36:S32

Geyer R, Jambeck JR, Law KL (2017) Production, use, and fate of all plastics ever made. Sci Adv 3(7):e1700782

Government of Canada (2019) Canada to ban harmful single-use plastics and hold companies responsible for plastic waste. https://pm.gc.ca/en/news/newsreleases/2019/06/10/canada-ban-harmful-single-use-plastics-and-holdcompanies-responsible. Accessed 15 Sep 2020

Government of Canada (2020) Canada one-step closer to zero plastic waste by 2030 https://www.canada.ca/en/environment-climate-change/news/2020/10/canadaone-step-closer-to-zero-plastic-waste-by-2030.html. Accessed 15 Sep 2020

Government of Nova Scotia (2019) Bill 152 Plastic Bags Reduction Act. https:// nslegislature.ca/legc/bills/63rd_2nd/1st_read/b152.htm. Accessed 15 Sep 2020

Government of Prince Edward Island (2020) Plastic Bag Reduction. https://www. princeedwardisland.ca/en/information/environment-water-and-climatechange/plastic-bag-reduction. Accessed 15 Sep 2020

Hajizadeh M, Mitnitski A, Rockwood K (2016) Socioeconomic gradient in health in Canada: is the gap widening or narrowing? Health Pol 120(9):1040-1050

Hanss D, Böhm G (2012) Sustainability seen from the perspective of consumers. Int J Consum Stud 36(6):678-687

Hartley BL, Holland M, Pahl S et al. (2015) How to communicate with stakeholders about marine litter-A short guide to influencing behavioural change. Plymouth University: Plymouth University Press, UK, http://www.marlisco.eu/ how-to-communicate-with-stakeholders-guide.en.html Accessed 15 Sep 2020

Herbes C, Beuthner C, Ramme I (2018) Consumer attitudes towards biobased packaging-A cross-cultural comparative study. J Clean Prod 194:203-218

Jambeck JR, Geyer R, Wilcox C et al. (2015) Plastic waste inputs from land into the ocean. Science 347(6223):768-771

Jia L, Evans S, van der Linden S (2019) Motivating actions to mitigate plastic pollution. Nat Commun 10(1):4582

Karbalaei S, Hanachi P, Walker TR et al. (2018) Occurrence, sources, human health impacts and mitigation of microplastic pollution. Environ Sci Pollut Res 25 (36):36046-36063 
Karbalaei S, Golieskardi A, Binti Hamzah H et al. (2019) Abundance and characteristics of microplastics in commercial marine fish from Malaysia. Mar Pollut Bull 148:5-15

Karbalaei S, Hanachi P, Rafiee G et al. (2021) Toxicity of polystyrene microplastics on juvenile Oncorhynchus mykiss (rainbow trout) after individual and combined exposure with chlorpyrifos. J Haz Mat 403:123980

Ketelsen M, Janssen M, Hamm U (2020) Consumers' response to environmentallyfriendly food packaging-A systematic review. J Clean Prod 254:120123

Lindh H, Olsson A, Williams H (2016) Consumer perceptions of food packaging: contributing to or counteracting environmentally sustainable development? Packag Technol Sci 29(1):3-23

Liu Z, Adams M, Walker TR (2018) Are exports of recyclables from developed to developing countries waste pollution transfer or part of the global circular economy? Resour Conserv Recycl 136:22-23

Marchildon J (2019) Another Canadian province just banned single-use plastic bags. https://www.globalcitizen.org/en/content/nova-scotia-plastic-bag-ban/. Accessed 15 Sep 2020

Molina-Besch K, Wikström F, Williams H (2019) The environmental impact of packaging in food supply chains-does life cycle assessment of food provide the full picture? Int J LCA 24(1):37-50

Naud D, Généreux M, Bruneau JF et al. (2019) Social participation in older women and men: differences in community activities and barriers according to region and population size in Canada. BMC Public Health 19(1):1124

Pahl S, Wyles KJ (2017) The human dimension: how social and behavioural research methods can help address microplastics in the environment. Anal Methods 9(9):1404-1411

Plastics Europe, \& Association of Plastics Manufacturers (2017) Plastics-The Facts 2017. Brussels, Belgium: www.plasticseurope.org. Accessed 15 Sep 2020

Prata JC, Silva ALP, Da Costa JP et al. (2019) Solutions and integrated strategies for the control and mitigation of plastic and microplastic pollution. Int J Environ Res Public Health 16(13):2411

Prata JC, Silva AL, Walker TR et al. (2020) COVID-19 pandemic repercussions on the use and management of plastics. Environ Sci Technol 54(13):7760-7765

Rokka J, Uusitalo L (2008) Preference for green packaging in consumer product choices-do consumers care? Int J Consum Stud 32(5):516-525

Sagan A (2019) Sobeys phasing out plastic bags from all stores by February, 2020. https://www.theglobeandmail.com/business/article-sobeys-phasing-outplastic-bags-from-all-stores-by-february-2020/. Accessed 15 Sep 2020

Schnurr REJ, Alboiu V, Chaudhary M et al. (2018) Reducing marine pollution from single-use plastics (SUPs): a review. Mar Pollut Bull 137:157-171

Scott L, Vigar-Ellis D (2014) Consumer understanding, perceptions and behaviours with regard to environmentally friendly packaging in a developing nation. Int J Consum Stud 38(6):642-649

Silva ALP, Prata JC, Walker TR et al. (2020) Rethinking and optimising plastic waste management under COVID-19 pandemic: policy solutions based on redesign and reduction of single-use plastics and personal protective equipment. Sci Total Environ 742:140565

Silva ALP, Prata JC, Walker TR et al. (2021) Increased plastic pollution due to COVID19 pandemic: challenges and recommendations. Chem Eng J 405:126683

Srivastava SK (2007) Green supply-chain management: a state-of-the-art literature review. Int J Manag Rev 9(1):53-80

Statistics Canada (2019) Waste diversion in Canada by type. https://www150. statcan.gc.ca/t1/tbl1/en/tv.action?pid=3810003401. Accessed 15 Sep 2020

United Nations Environment Program (UNEP) (2014) Valuing plastics: the business case for measuring, managing and disclosing plastic use in the consumer goods industry. https://wedocs.unep.org/handle/20.500.11822/9238. Accessed 15 Sep 2020

United Nations Environment Program (UNEP) (2018) Single-use plastics: a roadmap for sustainability. https://www.unenvironment.org/resources/report/single-useplastics-roadmap-sustainability. Accessed 15 Sep 2020

Walker TR (2018) China's ban on imported plastic waste could be a game changer. Nature 553(7689):405
Walker TR (2020) COVID-19 plastic pollution pandemic. SSRN 3739955

Walker TR (2019) Citizen science could help address Canada's plastic pollution problem. https://theconversation.com/citizen-science-could-help-address-canadasplastic-pollution-problem-121787. Accessed 15 Sep 2020

Walker TR, Xanthos D (2018) A call for Canada to move toward zero plastic waste by reducing and recycling single-use plastics. Resour Conserv Recycl 133:99-100

Walker TR, McKay DC (2021) Comment on "Five Misperceptions Surrounding the Environmental Impacts of Single-Use Plastic". Environ Sci Technol 55 (2):1339-1340

Weinhofer G, Hoffmann VH (2010) Mitigating climate change-how do corporate strategies differ? Bus Strat Environ 19(2):77-89

World Economic Forum, Ellen MacArthur Foundation, and McKinsey and Company (2016) The new plastics economy-rethinking the future of plastics. Retrieved from https://www.ellenmacarthurfoundation.org/assets/downloads/ EllenMacArthurFoundation_TheNewPlasticsEconomy_Pages.pdf. Accessed 15 Sep 2020

Worm B, Lotze HK, Jubinville I et al. (2017) Plastic as a persistent marine pollutant. Annu Rev Environ Resour 42:1-26

Wyles KJ, Pahl S, Carroll L et al. (2019) An evaluation of the fishing for litter (FFL) scheme in the UK in terms of attitudes, behavior, barriers and opportunities. Mar Pollut Bull 144:48-60

Xanthos D, Walker TR (2017) International policies to reduce plastic marine pollution from single-use plastics (plastic bags and microbeads): a review. Mar Pollut Bull 118(1-2):17-26

\section{Acknowledgements}

This study was supported with financial contributions from the Agri-Food Analytics Lab at Dalhousie University and the Angus Reid Institute in Canada.

\section{Competing interests}

The authors declare no competing interests.

\section{Additional information}

Supplementary information The online version contains supplementary material available at https://doi.org/10.1057/s41599-021-00747-4.

Correspondence and requests for materials should be addressed to T.R.W.

Reprints and permission information is available at http://www.nature.com/reprints

Publisher's note Springer Nature remains neutral with regard to jurisdictional claims in published maps and institutional affiliations.

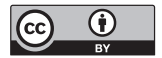

Open Access This article is licensed under a Creative Commons Attribution 4.0 International License, which permits use, sharing, adaptation, distribution and reproduction in any medium or format, as long as you give appropriate credit to the original author(s) and the source, provide a link to the Creative Commons license, and indicate if changes were made. The images or other third party material in this article are included in the article's Creative Commons license, unles indicated otherwise in a credit line to the material. If material is not included in the article's Creative Commons license and your intended use is not permitted by statutory regulation or exceeds the permitted use, you will need to obtain permission directly from the copyright holder. To view a copy of this license, visit http://creativecommons.org/ licenses/by/4.0/.

(C) The Author(s) 2021 